Journal of Animal and Veterinary Advances 10 (5): 585-592, 2011

ISSN: $1680-5593$

(C) Medwell Journals, 2011

\title{
Molecular Cloning and Sequence Characterization and Tissue Transcription Profile Analyses of Three Novel Common Carp (Cyprinus carpio) Genes- $\mathrm{RaB7}$, $\mathrm{RaB8} a$ and $\mathrm{RDH} H \mathrm{l}$
}

\author{
Kong Lingfu and BI Baoliang \\ College of Animal Science and Technology, Yunnan Agricultural University, \\ 650201 Kunming, P.R. China
}

\begin{abstract}
The complete coding sequences of three common carp genes $R A B 7, R A B 8 A$ and $R D H 1 L$ were amplified using the Reverse Transcriptase Polymerase Chain Reaction (RT-PCR) based on the sequence information of the zebrafish and referenced highly homologous common carp ESTs. The sequence analyses of these three genes revealed that common carp $R A B 7$ gene encodes a protein of 204 amino acids which has high homology with the RAB family member rab-7 (RAB7) of fifteen species: Atlantic salmon (97\%), zebrafish (91\%), sheep (90\%), western clawed frog (89\%), red jungle fowl (90\%), African clawed frog (88\%), human (89\%), $\operatorname{dog}(89 \%)$, horse (89\%), Sumatran orangutan $(89 \%)$, cattle (89\%), rat (89\%), mouse (89\%), Aiptasia pulchella $(88 \%)$ and rabbit $(87 \%)$. The common carp $R A B 8 A$ gene encodes a protein of 207 amino acids which has high homology with the cmember RAS oncogene family rab8a (RAB8A) of eight species: zebrafish (98\%), human $(92 \%)$, dog (92\%), cattle (92\%), mouse (91\%), rat (91\%), Sumatran orangutan $(91 \%)$ and chicken $(87 \%)$. The common carp RDHL gene encodes a protein of 319 amino acids that has high homology with tthe retinol dehydrogenase 1, like (RDH1L) of two species: zebrafish (83\%) and Atlantic salmon (65\%). Phylogenetic tree analysis revealed that the common carp RAB8A and $\mathrm{RDH} 1 \mathrm{~L}$ have closer genetic relationships with the zebrafish RAB8A and RDH1L but the common carp RAB7 has a closer genetic relationship with the RAB7 of Atlantic salmon. The tissue transcription profile analyses indicated that that the common carp $R A B 7, R A B 8 A$ and $R D H 1 L$ genes are generally but differentially expressed in the detected tissues including in tissues including muscle, heart, brain, skin, gills, eye, fin. These data serve as a foundation for further research on these three genes.
\end{abstract}

Key words: Common carp, RAB7, RAB8A, RDH1L, tissue transcription profile, China

\section{INTRODUCTION}

RAB7 is a small Rab GTPase that regulates vesicular traffic from early to late endosomal stages of the endocytic pathway. GTPase Activating Proteins (GAPs) interact with GTP-bound Rab and accelerate the hydrolysis of GTP to GDP.

Guanine nucleotide Exchange Factors (GEFs) interact with GDP-bound Rabs to promote the formation of the GTP-bound state. Rabs are further regulated by Guanine nucleotide Dissociation Inhibitors (GDIs) which facilitate Rab recycling by masking C-terminal lipid binding and promoting cytosolic localization (Rojas et al., 2008; Patel et al., 2008; Spinosa et al., 2008).

RAB8A is a member of the RAS superfamily which are small GTP/GDP-binding proteins with an average size of 200 amino acids. The RAS related proteins of the $\mathrm{RAB} / \mathrm{YPT}$ family may play a role in the transport of proteins from the endoplasmic reticulum to the Golgi and the plasma membrane (Shisheva et al., 1999; Hattula and Peranen, 2000; Hattula et al., 2002).

$R D H 1 L$ is another gene that had been demonstrated to be play an important roles in the aexocrine pancreas development, gut morphogenesis, metabolic process, oxidation reduction, pectoral fin morphogenesis, pectoral fin morphogenesis, retinol metabolic process, skeletal development (Nadauld et al., 2005).

Based on these described above these three genes are associated with important biological functions. To date, the common carp $R A B 7, R A B 8 A$ and $R D H 1 L$ genes have not been reported.

The objective of this study was to clone and analyze the coding sequences of common carp $R A B 7, R A B 8 A$ and $R D H 1 L$ genes and determine their tissue transcription profiles. The data obtained will serve as a basis for understand these common carp genes.

Corresponding Author: Kong Lingfu, College of Animal Science and Technology, Yunnan Agricultural University, 650201 Kunming, P.R. China 


\section{MATERIALS AND METHODS}

Samples collection, RNA extraction and first-strand cDNA synthesis: The tissue samples of muscle, heart, brain, skin, gills, eye, fin were obtained from six (about $3 \mathrm{~kg}, 3$ females and 3 males) local common carps in Yunnan province of China. Total RNA extraction and first strand cDNA synthesis for these tissue samples were performed using methods previously described (Liu et al., 2008). Briefly, total RNA was extracted using the TRIzol Reagent Total RNA Extraction Kit (GIBCO, USA). DNase I treatment was done before continuing with the first-strand cDNA synthesis. For each RNA sample, a single reverse transcription reaction was set up and then the efficiency of reverse transcription was checked on $1 \%$ agrose/EtBr gel.

Isolation of the common carp $R A B 7, R A B 8 A$ and $R D H 1 L$ genes: RT-PCR was performed to amplify complete coding sequences of these three common carp genes using the cDNA obtained from the pooled tissues above. The $20 \mu \mathrm{L}$ reaction system was $2.0 \mu \mathrm{L}$ cDNA (pooled), $2.0 \mu \mathrm{L} 2 \mathrm{mM}$ mixed dNTPs, $2.0 \mu \mathrm{L} 10 \times$ Taq DNA polymerase buffer, $1.2 \mu \mathrm{L}, 25 \mathrm{mM} \mathrm{MgCl}_{2}, 1.0 \mu \mathrm{L} 10 \mathrm{mM}$ forward primer, $1.0 \mu \mathrm{L}$ $10 \mathrm{mM}$ reverse primer, 2.0 units of Taq DNA polymerase $(1 \mathrm{U} / 1 \mu \mathrm{L}$ ) and $9.8 \mu \mathrm{L}$ sterile water. The primers for common carp $R A B 7$ gene isolation were designed based on the coding sequences from zebrafish $R A B 7$ gene and their highly homologous common carp EST sequences (GeneBank numbers CA969330, CA970203 andEC392463). Similarly, the primers for common carp $R A B 8 A$ gene isolation were designed based on the coding sequences from zebrafish $R A B 8 A$ gene and their highly homologous common carp EST sequences (Genbank numbers EC393638 and EX882991). The primers for isolating the common carp $R D H 1 L$ gene were designed based on the coding sequences from zebrafish $R D H 1 L$ genes and their highly homologous common carp EST sequences (GenBank numbers CF662451 and EX880878). These primers were all designed to amplify the complete CDS from start codon to the stop codon) and partial flanking sequences for these three genes. These primer sequences and their annealing temperature for RT-PCR reaction are shown in Table 1.

The PCR products for common carp RAB7, RAB8A and RDH1L cDNAs were then cloned into PMD18-T vector and sequenced bidirectionally with the commercial fluorometric method. At least five independent clones were sequenced for every gene.

RT-PCR for transcription profile: RT-PCR for transcription profile analyses were performed using the cDNA obtained from the specific tissues above as described by Liu and Xiong (2007). The housekeeping
Table 1: Primers for common carp RAB7, RABSA, RDHIL, actin genes and their annealing temperatures

\begin{tabular}{|c|c|c|}
\hline Gene & Primer sequence & $\mathrm{Ta} /{ }^{\circ} \mathrm{C}$ \\
\hline \multirow[t]{2}{*}{$R A B 7$} & Forward:5'-GCAGCAGATCGTTAAACC-3' & \\
\hline & Reverse:5'-GGATCTCTCCCTTTCCCA-3' & 57 \\
\hline \multirow[t]{2}{*}{$R A B S A$} & Forward:5'-GGCTGAAGTACCGGGCGG-3' & \\
\hline & Reverse:5'AGCATAGTCCAGTCGTGT-3 & 56 \\
\hline \multirow[t]{2}{*}{ RDHIL } & 5'-CACTTTTCTTATAAAAACAAT-3' & \\
\hline & CATCAATATGCTG & 51 \\
\hline \multirow[t]{2}{*}{ Actin } & Forward: 5'-GAGCGTGGTTATTCTTTCG-3' & \\
\hline & Reverse:5'-TAGGCGGTCTCATGGATT-3' & 54 \\
\hline
\end{tabular}

gene, actin was used as an internal control. The primers and annealing temperature for common carp actin gene (GeneBank number: AY309091) amplification is shown in Table 1. The size of the actin PCR fragment is $254 \mathrm{bp}$. To ensure that no false positive PCR fragments were generated from pseudogenes in the contaminating genomic DNA, actin primers were derived from different exons in the same gene. The primers for common carp $R A B 7, R A B 8 A$ and $R D H 1 L$ gene which were used to perform the RT-PCR for tissue transcription profile analyses were the same as the primers used for amplification in RT-PCR above. The $25 \mathrm{~L}$ reaction system was: $2.0 \mathrm{~L}$ pooled cDNA of each tissue $\left(100 \mathrm{ng} \mu \mathrm{L}^{-1}\right)$, $2.5 \mathrm{~L} 2 \mathrm{mM}$ mixed dNTPs, $2.5110 \times$ Taq DNA polymerase buffer, $2.5 \mathrm{~L} 25 \mathrm{mM} \mathrm{MgCl}_{2}, 2.0 \mathrm{~L} 10 \mathrm{mM}$ forward primer, $2.0 \mathrm{~L} 10 \mathrm{mM}$ reverse primer, 2.0 units of Taq DNA polymerase (1 U/1 L) and $9.5 \mathrm{~L}$ sterile water. The PCR program initially started with a $94^{\circ} \mathrm{C}$ denaturation for 4 min followed by 30 cycles of $94^{\circ} \mathrm{C} / 1 \mathrm{~min}, \mathrm{Ta}^{\circ} \mathrm{C}$ (Tablel ) $/ 1 \mathrm{~min}, 72^{\circ} \mathrm{C} / 1 \mathrm{~min}$ then $72^{\circ} \mathrm{C}$ extension for $10 \mathrm{~min}$, finally $4^{\circ} \mathrm{C}$ to terminate the reaction. Every PCR was repeated 5 times.

Sequence analysis: The gene analysis for cDNA sequence was conducted using GenScan software (http://genes.mit.edu/GENSCAN.html). The protein prediction and analysis were performed using the Conserved Domain Architecture Retrieval Tool of Blast at the National Center for Biotechnology Information (NCBI) server (http://www.ncbi.nlm.nih.gov/BLAST) and the ClustalW software (http://align.genome.jp/). The theoretical isoelectric point (pI) and Molecular weight $(\mathrm{Mw})$ of proteins was computed using the Compute pI/Mw Tool (http://www.expasy.org/tools/pi_tool.html).

\section{RESULTS AND DISCUSSION}

Isolation results for common carp $R A B 7, R A B 8 A$ and RDH1L gene: Through RT-PCR with pooled tissue cDNAs for common carp $R A B 7, R A B 8 A$ and $R D H 1 L$ gene, the resulting PCR products were 742,717 and $1063 \mathrm{bp}$ (Fig. 1). 

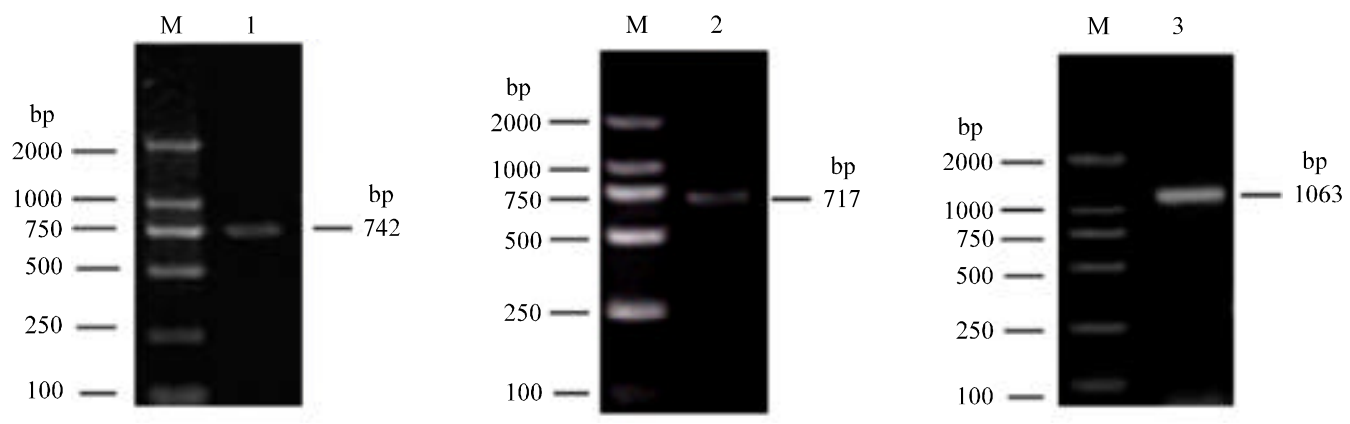

Fig. 1: Isolation results for common carp $R A B 7, R A B 8 A$ and $R D H 1 L$ genes. M, DL2000 DNA markers; 1) PCR product for common carp $R A B 7$ gene; 2) PCR product for common carp $R A B 8 A$ gene; 3) PCR product for common carp $R D H 1 L$ gene

Sequence analysis: These cDNA nucleotide sequence analysis using the BLAST software revealed that these genes were not homologous to any of the known common carpgenes and they were then deposited into the GenBank database (Accession number: EU287430, EU287431 and EU295556). The sequence prediction was carried out using the GenScan software and results showed that the 742,717 and $1063 \mathrm{bp}$ cDNA sequences represented three single genes which encoded 204, 207, 319 amino acids, respectively. The theoretical isoelectric point $(\mathrm{pI})$ and Molecular weight $(\mathrm{Mw})$ of these deduced proteins of these three common carpgenes were computed using the Compute $\mathrm{pI} / \mathrm{Mw}$ Tool. The $\mathrm{pI}$ of common carpRAB7, RAB8A and RDH1L are 6.35, 8.99 and 8.93, respectively. The molecular weights of these three putative proteins are $23089.19,23667.21$ and 36033.34 , respectively.

Further Blast analysis of these proteins revealed that common carp RAB7 has high homology with the $\mathrm{RAB}$ family member rab-7 (RAB7) of fifteen species: Atlantic salmon (ACI34062, 97\%), zebrafish (NP_957222, 91\%), sheep (NP_001119836, 90\%), western clawed frog (NP_001 008026, 89\%), red jungle fowl(XP_414359, 90\%), African clawed frog (NP_001087006, 88\%), human (NP_004628, 89\%), dog (NP_001003316, 89\%), horse (XP_001488351, 89\%), Sumatran orangutan (NP_001127416, 89\%), cattle (NP_001 030253, 89\%), rat (NP_076440, 89\%), mouse (CAA61797, 89\%), aiptasia pulchella (JC8006, 88\%) and rabbit(NP_001075503, 87\%). The common carp RAB8A has high homology with the member RAS oncogene family rab8a (RAB8A) of eight species: zebrafish (NP_001083031, 98\%), human (NP_005361，92\%)， dog (XP_855569, 92\%), cattle (NP_001098951, 92\%), mouse (P55258, 91\%), rat (NP_446450, 91\%), Sumatran orangutan (NP_001127003, 91\%) and chicken (Q5F470, 87\%). The common carp RDH1L has high homology with the retinol dehydrogenase 1, like (RDH1L) of two species: zebrafish (NP_955903, 83\%) and Atlantic salmon (ACI67927, 65\%) (Fig. 2-7).

Based on the results of the alignment of RAB7, RAB8A and RDH1L, phylogenetic trees were constructed using the Dendrogram procedure of ClustalW software (http://align.genome.jp/) as shown in Fig. 8-10.

The phylogenetic tree analysis revealed that the common carp RAB8A and RDH1L have closer genetic relationships with the zebrafish RAB8A and RDH1L but the common carp RAB7 has a closer genetic relationship with the RAB7 of Atlantic salmon.

Tissue transcription profile: Tissue transcription profile analysis revealed that compared to the expression of common carp actin gene, the common carp $R A B 7, R A B 8 A$ and $R D H I L$ genes are generally but differentially expressed in the detected tissues including in tissues including muscle, heart, brain, skin, gills, eye, fin (Fig. 11).

Comparative genomics research has revealed that virtually all (99\%) of the protein-coding genes in humans align with homologs in mouse and over $80 \%$ are clear $1: 1$ orthologs (Hardison, 2003). This extensive conservation in protein-coding regions implies that this conservation of protein-coding sequences may be expected in different fish species including zebrafish and common carps. With the completion of zebrafish whole genome sequencing and development of modern bioinformatics, many more specific databases such as NCBI common carp EST database were established.

These along with different convenient analysis tools make it much easier to find the common carp EST sequences highly homologous to some protein-coding sequences of zebrafish. These tools also make it easer to isolate the encoding regions of some common carp genes based on the protein-coding sequence information of zebrafish and the highly homologous common carp EST sequence information. 


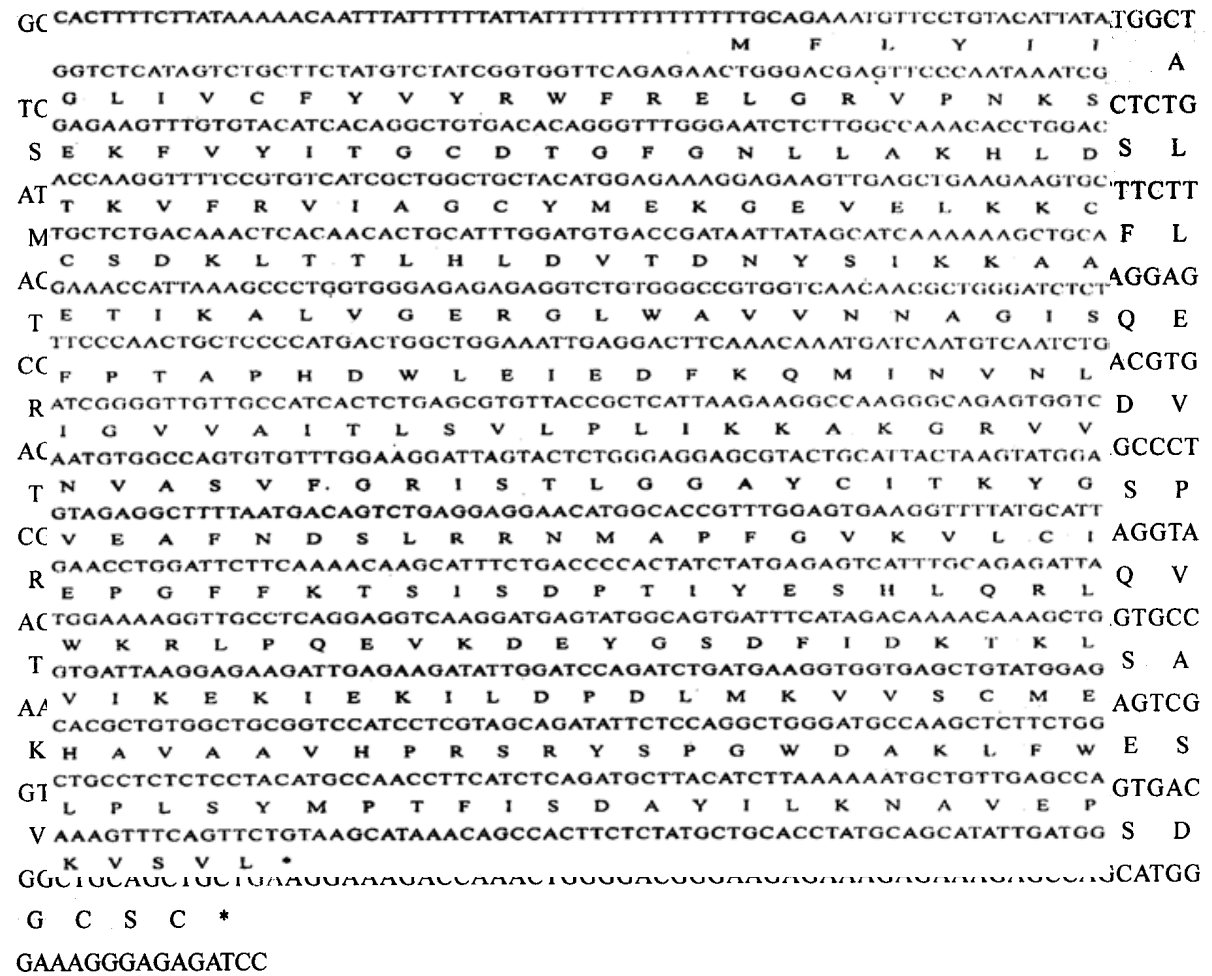

Fig. 2: The complete coding sequence of common carp $R A B 7$ gene and its encoding amino acids * indicates the stop codon

GGCTGAAGTACCGGGCGGGATTTCCGCAATACATTAAGTATGGCGAAGACCTACGATTATTTGTTTAAA

$$
\begin{array}{lllllllllll}
M & \text { A } & \text { K } & \text { T } & \text { Y } & \text { D } & \text { Y } & \text { L } & \text { F } & \text { K }
\end{array}
$$

CTGCTGTTAATCGGGGATTCCGGCGTCGGGAAGACCTGTGTGCTGTTCAGATTCTCGGAGGATGCC

$\begin{array}{llllllllllllllllllllll}\text { L } & \text { L } & \text { L } & \text { I } & G & \text { G } & \text { S } & \text { G } & \text { V } & \text { G } & \text { K } & \text { T } & \text { C } & \text { V } & \text { L } & \text { F } & \text { R } & \text { F } & \text { S } & \text { E } & \text { D } & \text { A }\end{array}$

TTTAACTCGACGTTTATTTCGACGATAGGTATTGATTTCAAGATCAGGACAATAGAACTAGATGGC

$\begin{array}{lllllllllllllllllllllll}\text { F } & \text { N } & \text { S } & \text { T } & \text { F } & \text { I } & \text { S } & \text { T } & \text { I } & G & \text { I } & \text { D } & \text { F } & \text { K } & \text { I } & \text { R } & \text { T } & \text { I } & \text { E } & \text { L } & \text { D } & \text { G }\end{array}$

AAGAAGATAAAGTTACAGATATGGGACACGGCAGGACAGGAGCGATTCCGAACAATCACAACGGCG

$\begin{array}{lllllllllllllllllllllll}K & K & I & K & \text { L } & \text { Q } & \text { I } & \text { W } & \text { D } & \text { T } & \text { A } & G & \text { Q } & \text { E } & \text { R } & \text { F } & \text { R } & \text { T } & \text { I } & \text { T } & \text { T } & \text { A }\end{array}$

TATTACAGAGGTGCAATGGGGATCATGCTGGTTTATGATATTACTAATGAGAAATCATTTGACAAC

$\begin{array}{lllllllllllllllllllllll}\mathrm{Y} & \mathrm{Y} & \mathrm{R} & \mathrm{G} & A & \mathrm{M} & \mathrm{G} & \mathrm{I} & \mathrm{M} & \mathrm{L} & \mathrm{V} & \mathrm{Y} & \mathrm{D} & \mathrm{I} & \mathrm{T} & \mathrm{N} & \mathrm{E} & \mathrm{K} & \mathrm{S} & \mathrm{F} & \mathrm{D} & \mathrm{N}\end{array}$

ATCAAAAACTGGATCCGAAACATAGAGGAGCATGCATCAGCGGATGTAGAAAAAATGATTTTGGGG

$\begin{array}{lllllllllllllllllllllll}\text { I } & K & N & N & \text { W } & \text { I } & R & \text { N } & \text { I } & \text { E } & \text { E } & \text { H } & \text { A } & \text { S } & \text { A } & \text { D } & \text { V } & \text { E } & \text { K } & \text { M } & \text { I } & \text { L } & \text { G }\end{array}$ AACAAATGTGACATTAATGAGAAGAGGCAGGTGTCTAAAGACAGAGGCGAGAAGCTGGCGTTAGAG $\begin{array}{llllllllllllllllllllll}N & K & C & D & I & N & E & K & R & Q & V & S & K & D & R & G & E & K & L & A & L & E\end{array}$ TATGGCATCAAGTTCATGGAGACGAGTGCGAAGGCTAATATCAACGTTGAGAACTCATTCTTAACG $\begin{array}{llllllllllllllllllllll}\text { Y } & G & I & K & \dot{F} & M & E & T & S & A & K & A & N & I & N & V & E & N & S & F & L & T\end{array}$ CTCGCCAGAGACATAAAATCAAAGATGGACACGAAATTGGAGGGGAACAATCCTCAGAGCAGCAAC $\begin{array}{llllllllllllllllllllll}\text { L } & \text { A } & R & \text { D } & \text { I } & \text { K } & \text { S } & \text { K } & \text { M } & \text { D } & \text { T } & \text { K } & \text { L } & \text { E } & \text { G } & \text { N } & \text { N } & \text { P } & \text { Q } & \text { S } & \text { S } & \text { N }\end{array}$ CATGGAGTGAAAATTACCACTGAACAGCAGAAAAAGAGCAGCTTCTTTCGCTGTGTGCTACTGTGA $\begin{array}{lllllllllllllllllllllll}\mathrm{H} & \mathrm{G} & \mathrm{V} & \mathrm{K} & \mathrm{I} & \mathrm{T} & \mathrm{T} & \mathrm{E} & \mathrm{Q} & \mathrm{Q} & \mathrm{K} & \mathrm{K} & \mathrm{S} & \mathrm{S} & \mathrm{F} & \mathrm{F} & \mathrm{R} & \mathrm{C} & \mathrm{V} & \mathrm{L} & \mathrm{L} & *\end{array}$ AGATCAAGGCCTTACTGTCCGCCGTCCGTGGGCTGGACACGACTGGACTATGCT

Fig. 3: The complete coding sequence of common carp $R A B 8 A$ gene and its encoding amino acids *indicates the stop codon 


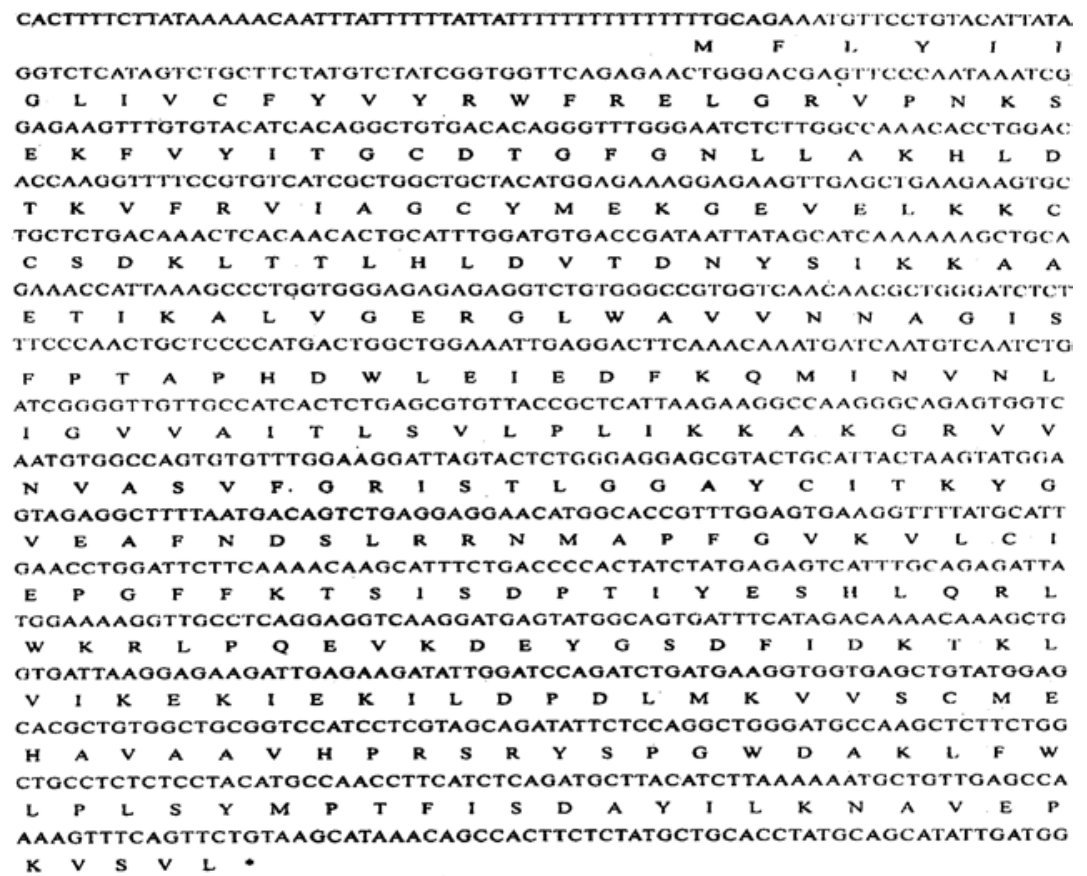

Fig. 4: The complete coding sequence of common carp RDH1L gene and its encoding amino acids *indicates the stop codon
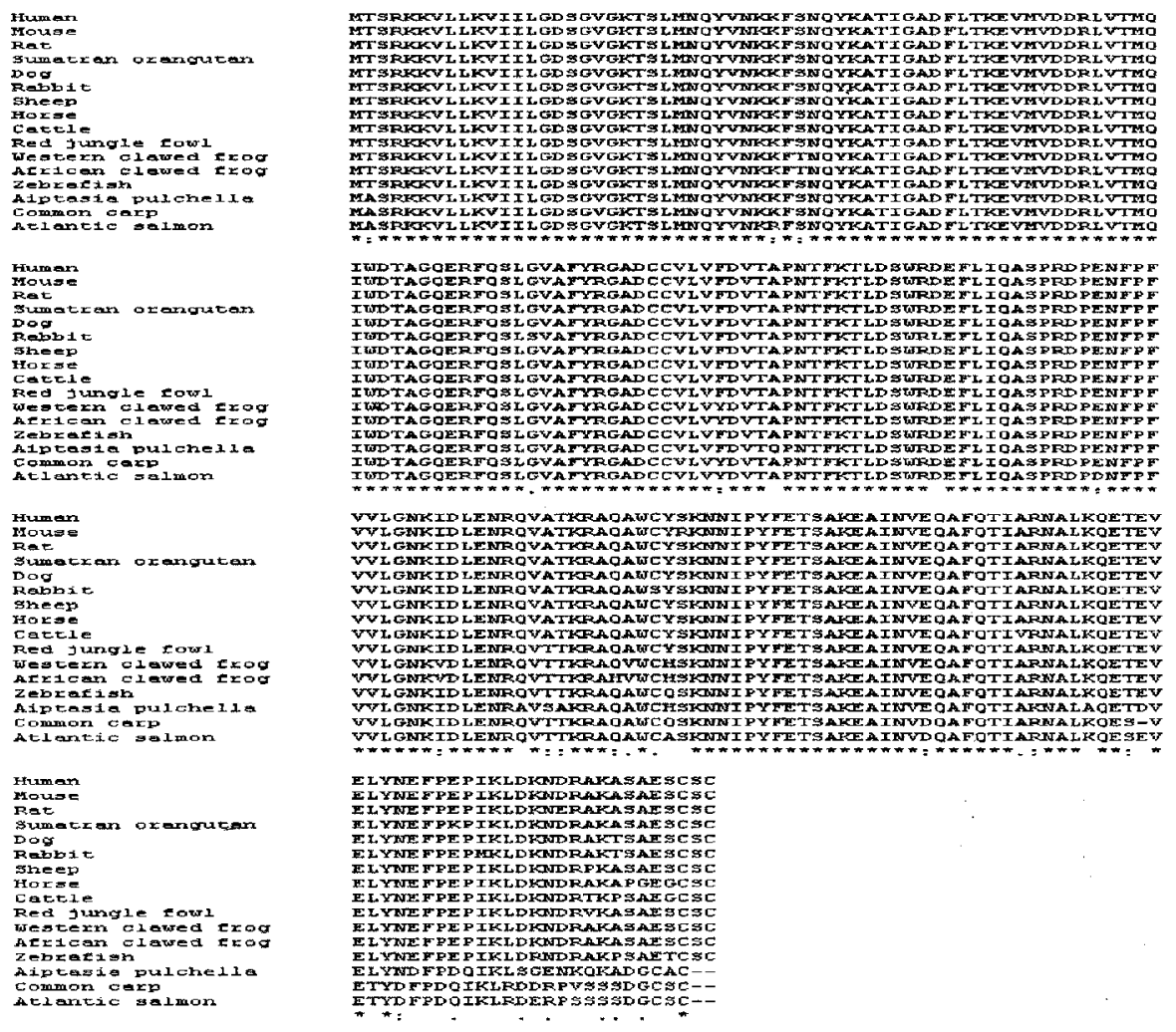

Fig. 5: The alignment of the protein encoded by common carp $R A B 7$ gene and other fifteen kinds of $\mathrm{RAB} 7$ from Atlantic salmon, zebrafish, sheep, western clawed frog, red jungle fowl, African clawed frog, human, dog, horse, Sumatran orangutan, cattle, rat, mouse, Aiptasia pulchella and rabbit 


Human_Dog
Sumatran orangutan
Cattle
Chicken
Mouse_Rat
Common carp
Zebrafish
Human_Dog
Sumatran orangutan
Cattle
Chicken
Mouse_Rat
Common carp
Zebrafish
Human_Dog
Sumatran orangutan
Cattle
Chicken
Mouse_Rat
Common carp
Zebrafish
Human_Dog
Sumatran orangutan
Cattle
Chicken
Mouse_Rat
Common carp
Zebrafish
f

MAKTYDYL FKLLL IGDSGVGKTCVL FRFSEDAFNSTFISTIGID FKIRTIELDGKRIKLQ MAKTYDY L FKL LL I GD SGUGKTCVL FRFSEDAFNSTFISTIGID FKIRTIELDGKRIKLQ MAKTYDYL FKL L L I GD SGVGKTCVL FRF SEDAFNSTFI STI GID FKIRTIELDGKRIKLQ MAKTYDYL FKL L L IGD SGVGKTCALFRFSEDAFMATF ISTIGID FKIRTIELDGKRIKLO MAKTYDYL FKL L L I GD SGVGKTCVLFR FSEDAFNSTFISTIGID FKIRTIE LDGKRIKLO MAKTYD YL FKL L L IGD S GVGKTCVL FRFSEDAFNSTFI STIGID FKIRTIE LDGKKIKLQ MAKTYD YL FKL L L IGD SGVGKTCVL FRFSEDAFNSTF ISTIGID FKIRTIE LDGKKIKLQ

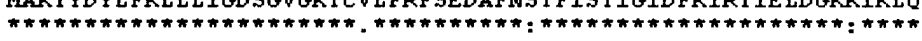

IWDTAGOERFRTITTAYYRGAMGIML VYDITNEKS FDNIRNWIRNIEEHASADVEKMI LG IUD TA GQER FRT ITTAYYRGAMG IML VYD ITNEKS FD NIRNWIRNIEEHA SADVEKMI LG IUDTAGQER FRTITTAYYRGAMG IML VYD ITNEKS FDNIRNWIRNIEEHA SADVEKMI I G IWDTAGOER FRTITTAYYRGAMGIML VYO ITNEKS FENIRNWVRNIEEHAS PDVEKMI I G IUDTAGQER FRTITTAYYRGAMG IML VYD ITNEKS FD NIRNWIRNIEEHA. SADVEKMI LG IUDTAGQER FRTITTAYYRGAMG IML VYD ITNEKS FDNI KNUIRN IEEHASADVEKMI LG

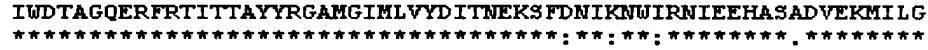

NKCDVNDKRQVSKERGEKLALDYGIKFMETSAKANINVENAFFTLARD IKAKRWKKLEGN NKRD VNDKRQVSKERGEKLALDYGIKFIETSAKANINVE NAFFTLARD IKAKMDKKLEGN NKCDVNDKROVSKERGEKLALDYGIKFMETSAKANINYTNA FYTLARD IKAKMDKKLEGN MKCDANDKROVSRE QGEKLAAS FGIKFMETSAKANINIENA FYTLARD IKAKMDKKLE GN NKCDVNDKRQVSKERGEKLALDYGIKFMET TAKANINYENA F FTLARD IKAKMIDKKLE GN NKCD INEKROVSKDRGEKLALEYGIKFWETSAKAN INVENS FL TLARD IKSKMDTKLE GN NKCD INEKROVSKDRGEKLALEYGIKFMETSAKANINVTNA FL TLARD IKAKMI TKLE GN

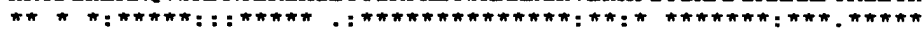

SPOGSNQGVKITPDQQKRS SFRCVLL SPQGSNQGVKITPDQQKRS S FFRCVLL SPQGSNQGVKITPDQQKRS S FFRCVLL SPQGSNQGYKITPDQQKKSSFFRCVLL SPQGSSHGVKITVEQQKRTS FFRCSLL NPQSSNHGVKITTEQQKKSS FFRCVLL

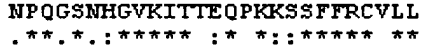

Fig. 6: The alignment of the protein encoded by common carp $R A B 8 A$ gene and other eight kinds of RAB8A from zebrafish, human, dog, cattle, mouse, rat, Sumatran orangutan and chicken

Common carp
Zebrafish
Atlantic salmon
Common carp
Zebrafish
Atlantic salmon
Common carp
Zebrafish
Atlantic salmon
Common carp
Zebrafish
Atlantic salmon
Common sarp
Zebrafish
Atlantic salmon
Common carp
Zebrafish
Atlantic salmon

MFLYIIGL IVC FYVYRWFRE L GRVPNKSEKFVY ITGCDTGFGNL LAKHLDTKV FRVIAGC MYL Y IAGL VWL FYVYRU FRE L GRVSNKSEKFVYITGCDTGFGNL LARHLDTKGFRYIAGC MFLYLLGLVVFYYLYRUFRE I PRVPDKGDKYVYITGCD SGFGNLLARHLDEL GFCVIASC

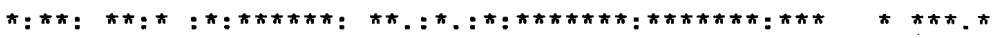

YMEKGEVE LKKC C SDKL TTLHLDVTDWYS IKKAAETIKALVGERGLWAVVNNAGISFPTA YSEKGEDE LKKIC SDRL ITLHLD VTDNEWVKKAAETIKS L VGOKGLWAVVNNAGIAFPTA FTEKGEED LRKAC SDR FTTLHLDVKKINESVDKAAAL IKDKVGARGLTAVMNHAGVAIP SA

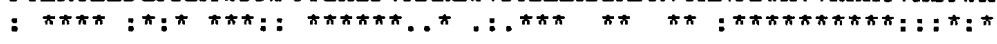

PHDULEIED FKOMINVNL IGWATTL SVLP L IKRAKGRVVNYASFGRISTLGGAYCITK PNDULEIED FTPMINVNLIGWIAVTLSVL PLIKKAKGRVVWVASVFGRISTLGGAYCITK PCDWLTIDDYKSMLDVN LWGVIAVTL SVL P IKKARGRVVNVASVFGRI SPVGGPYTVSK

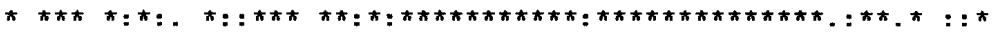

YGVEA FNDS LRRNMA P FGVKYLCIEPGFFKTSISD PTIYESHLQRLUKRL PQEVKDEYGS YGVEAFNDALRROMAP F GVKVLC IEP GFFKTIVTD FNIVESTLHRL WHKL PQEVKEYGS YGVEAFWD S LRRMLAP F GVKVLCIEPGF FKITVIDSYV L GKSIKQ L WEKMPQQVRDDYGP

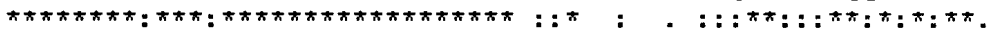

DFIDKTKL VIKEKIEKI LD PD LMKVVSCHEHAVAAVHPRSRYSP GUDAKL FUL PLSYMPT DYUDKTKLTAKE L LEKLADGD LMKVVS CKEHAVAAVHPRTRYS P GUDAKFFWL PL SYMPT DYLDKVD VMIREKLAKMSD TD LMKVVSCMEHAISAVRPRTRYSPGWDAKL FWI PMSYMPT

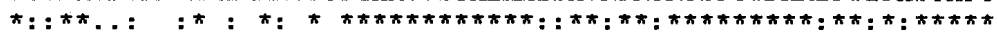

FISDAYILKWAVE PKVSVL FISDALLLKKAVQPKASIL GFADWLLLKEAIL PAKAVN $:::^{* \pi: *: * \quad::}$

Fig. 7: The alignment of the protein encoded by common carp RDH1L gene and other two kinds of RDH1L from zebrafish and Atlantic salmon

The present study cloned and analyzed the CDS sequences for three common carp genes. The data show that these common carp genes are highly similar to these zebrafish genes making the zebrafish a potential 


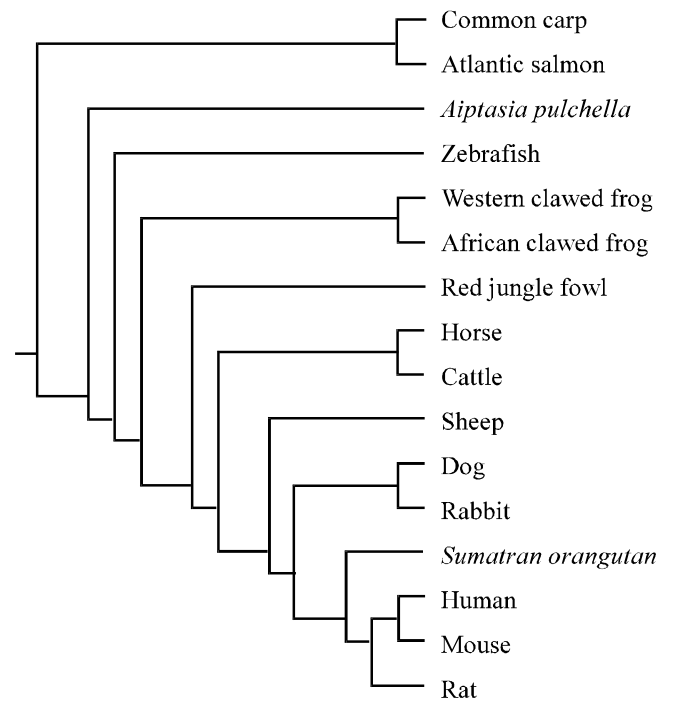

Fig. 8: The phylogenetic tree for five kinds of RAB7 from common carp, Atlantic salmon, zebrafish, sheep, western clawed frog, red jungle fowl, African clawed frog, human, dog, horse, Sumatran orangutan, cattle, rat, mouse, Aiptasia pulchella and rabbit

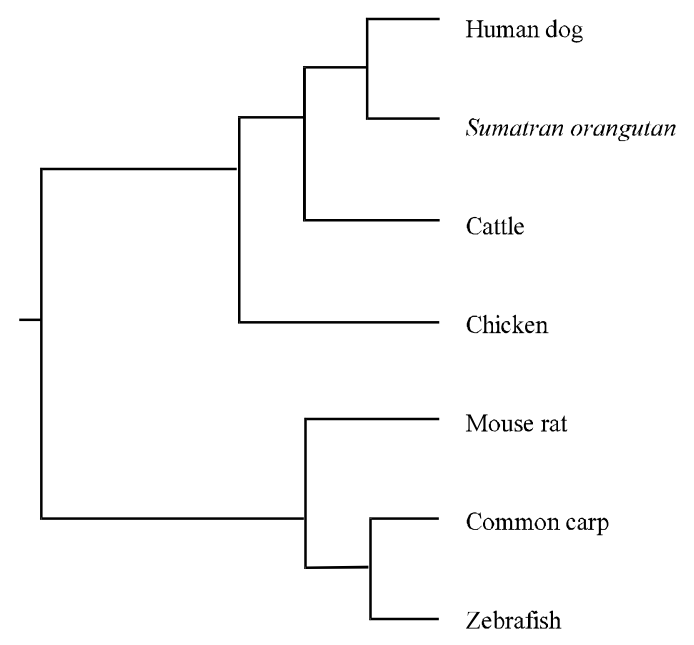

Fig. 9: The phylogenetic tree for five kinds of RAB8A from common carp, zebrafish, human, dog, cattle, mouse, rat, Sumatran orangutan and chicken

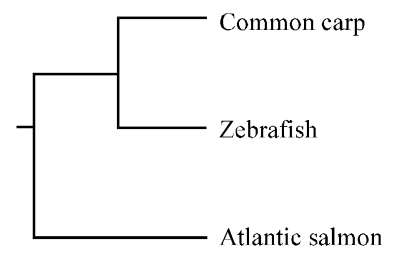

Fig. 10: The phylogenetic tree for four kinds of RDH1L from common carp, zebrafish and Atlantic salmon

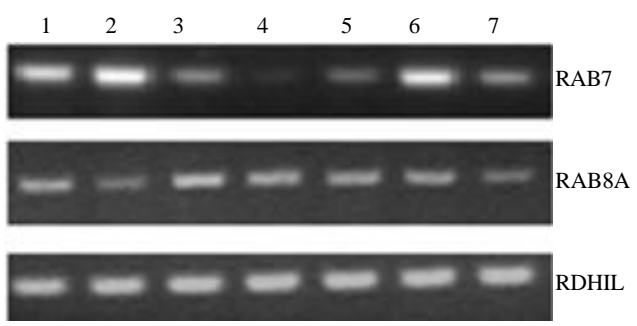

Fig. 11: Tissue transcription profile of common carp $R A B 7, R A B 8 A$ and $R D H 1 L$ gene. The actin expression is the internal control; 1) muscle; 2) heart; 3) brain; 4) skin; 5) gills; 6) eye; 7) fin

non-primate model for studying these common carp genes. From the tissue transcription profile analysis in the experiment it can be seen that these genes were obviously differentially expressed in some tissues.

Would there be some associations between the functions and mRNA differential expression in some tissues for these common carp genes? This needs to study furtherly.

\section{CONCLUSION}

In the study, we first isolated the common carp $R A B 7$, $R A B 8 A$ and $R D H 1 L$ genes and performed necessary sequence analysis and tissue transcription profile analysis. This established the primary foundation for further research on these three common carp genes.

\section{REFERENCES}

Hardison, R.C., 2003. Comparative genomics. PLoS Biol., 1: e $58-\mathrm{e} 58$.

Hattula, K. and J. Peranen, 2000. FIP-2, a coiled-coil protein, links Huntingtin to Rab8 and modulates cellular morphogenesis. Curr. Biol., 10: 1603-1606.

Hattula, K., J. Furuhjelm, A. Arffman and J.A. Peranen, 2002. A Rab8-specific GDP/GTP exchange factor is involved in actin remodeling and polarized membrane transport. Mol. Biol. Cell., 13: 3268-3280.

Liu, G.Y. and Y.Z. Xiong, 2007. Isolation, sequence analysis and expression profile of a novel porcine gene, NIP7, differentially expressed in the longissimus dorsi muscle tissues from meishan, meishan $\mathrm{x}$ large white cross and large white pigs. Mol. Biol. Rep., 344: 213-219. 
Liu, G.Y., S.Z. Gao, C.R. Ge and X. Zhang, 2008. CDNA cloning and tissue expression analyses of the encoding regions for three novel porcine genes-MJ1, CDC42 and NECD. Anim. Biotechnol., 19: 117-121.

Nadauld, L.D., D.N. Shelton, S. Chidester, H.J. Yost and D.A. Jones, 2005. The zebrafish retinol dehydrogenase, rdhl1, is essential for intestinal development and is regulated by the tumor suppressor adenomatous polyposis coli. J. Biol. Chem., 280: 30490-30495.

Patel, N., S.B. Singh, S.K. Basu and A. Mukhopadhyay, 2008. Leishmania requires Rab7-mediated degradation of endocytosed hemoglobin for their growth. Proc. Natl. Acad. Sci. USA., 105: 3980-3985.
Rojas, R., T. van Vlijmen, G.A. Mardones, Y. Prabhu and A.L. Rojas et al., 2008. Regulation of retromer recruitment to endosomes by sequential action of Rab5 and Rab7. J. Cell. Biol., 183: 513-526.

Shisheva, A., S.R. Chinni and C. DeMarco, 1999. General role of GDP dissociation inhibitor 2 in membrane release of Rab proteins: Modulations of its functional interactions by in vitro and in vivo structural modifications. Biochemistry, 38: 11711-11721.

Spinosa, M.R., C. Progida, A. de Luca, A.M.R. Colucci, P. Alifano and C. Bucci, 2008. Functional characterization of $\mathrm{Rab} 7$ mutant proteins associated with charcot-marie-tooth type $2 \mathrm{~B}$ disease. J. Neurosci., 28: 1640-1648. 